\title{
An Investigation on Consumer Sociability Behaviour on Facebook
}

\author{
Egle Vaiciukynaite ${ }^{1}$, Francesco Massara ${ }^{2}$, Rimantas Gatautis ${ }^{3}$
}

\author{
${ }^{1,3}$ Kaunas University of Technology \\ K. Donelaicio st. 73, LT-44029, Kaunas, Lithuania \\ E-mail.egle.vaiciukynaite@gmail.com,rimantas.gatautis@ktu.lt \\ ${ }^{2}$ International University of Languages and Media \\ Via Carlo Bo st. 1, Milano, Italy \\ E-mail.francesco.massara@iulm.it
}

cross'ref http://dx.doi.org/10.5755/j01.ee.28.4.15078

\begin{abstract}
The paper aims to investigate nuanced characteristics of messages (i.e., vividness, interactivity, emotionality) that foster consumer sociability behaviour in terms of likes, comments and shares on a company Facebook page. The data were obtained from an international hotel Facebook page between 14 January 2015 and 14 January 2016. The company messages (144) have been investigated analysing content and text using the Linguistic Inquiry and Word Count Software (LIWC). The results reveal that messages with a low or medium level of vividness exhibit higher levels of liking, commenting, and sharing. Messages with a medium level of interactivity also generate more comments and shares. Finally, emotionality is strongly related to consumer sociability behaviour increasing likes, comments and shares. Concerning vividness and interactivity the study presents counterintuitive results respect to mainstream literature and offers insights while recommending that additional research should be carried out. These new insights help companies to understand how to develop relationships with consumers on their official Facebook pages.
\end{abstract}

Keywords: Consumer Sociability Behaviour, Emoticon, Emoji, Emotional Text, Facebook, Interactivity, Messages, Vividness.

\section{Introduction}

"The key is to interact with Facebook users as friends rather than as marketing targets." Kwok, Yu (2013; p.91)

The continuous growth of SNSs provides virtual places enabling user interaction and sharing of information with one another. Moreover, SNSs have become a dominant medium for social interaction among users and have empowered consumers to take an active role as market players (Hennig-Thurau et al., 2010). Facebook is the most popular SNS with about 1,600 billion active users each month (Wagstaff, 2015; Smith, 2016).

Beyond the popularity of SNSs among consumers, they are increasingly used by companies. Companies wish to transmit marketing messages through SNSs engaging the customers in online conversations (Cvijikj \& Michahelles, 2013; Luarn et al., 2015). These online conversations are visible to a large audience and are unique due to their nature. For example, when a consumer comments on a company's post on Facebook, this action is visible to the consumer's entire network of close friends. These online conversations thus provide data which may be tracked by other consumers or even competitors. A recent study by Kumar et al., (2016) has shown the impact of company messages on customer profitability. Per the findings of the study, consumers who engage in conversation with companies on the SNSs contribute $\$ 1.02$ more to the company's profit than nonparticipating customers. Other studies (Gamboa \& Goncalves, 2014), have noted that Facebook is an essential tool in achieving customer loyalty.
A company message is a tool that fosters interaction with customers (Sabate et al., 2014). Recent studies examined the impact of companies' messages on consumer sociability on Facebook (Tafesse, 2015, Kwok et al., 2015). To date, however, there is little knowledge concerning which characteristics messages should have to stimulate sociability (Gensler et al., 2013; Su, Reynolds \& Sun, 2015). Sociability concerns likes, shares and comments on SNSs and its advantages are obvious in terms of customer engagement, therefore, companies should very be willing to invest in it.

Many empirical studies have examined product producing companies' messages on Facebook (De Vries et al., 2012; Cvijikj \& Michahelles, 2013; Tafesse, 2015; Luarn et al., 2015) and to a lesser extent these studies have been extended to service companies (Kwok \& Yu, 2013; Sabate et al., 2014; Kwok et al., 2015; Pelletier et al., 2015). There is, in fact, less knowledge about the characteristics of service companies' messages (Kwok \& Yu, 2013), which on the other hand is compensated by the fact that services are more interactive in general than product companies (Pelletier et al., 2015).

A few previous studies analyzed likes and comments (De Vries et al., 2012; Kwok \& Yu, 2013; Swani et al., 2013; Chauhan \& Pillai, 2013) focusing on cross-sectional data, but to our knowledge no studies on Facebook messages use longitudinal data. The current study uses a longitudinal analysis of consumers' sociability behaviour on a company's Facebook page to fill this gap.

This study is also innovative because it integrates quantitative content analysis while previous empirical research on consumer sociability behaviour has mainly been 
the result of qualitative research (De Vries et al., 2012; Cvijikj \& Michahelles, 2013; Luarn et al., 2015). More specifically, this research distinguished between different type of message content (e.g., informational, entertainment, remuneration, social). Respect to these studies, our analysis provides a more granular level of analysis at the level of implicit characteristics of the message (e.g., vividness, interactivity, emotionality). Text analysis research has been widely used in psychological studies (Tausczik \& Pennebaker, 2010; Bazarova et al., 2012; Settanni \& Marengo, 2015) in particular those investigating the language used on Facebook from the sender perspective (Carr et al., 2012; Settanni \& Marengo, 2015). To our knowledge, however, this is the first contribution using content analysis to study consumer sociability behaviour on a company's Facebook page.

The paper thus aims to investigate the characteristics of company messages that facilitate consumer sociability behaviour in terms of likes, comments and shares on company's Facebook page using a mixed research method.

The rest of the paper reviews the literature, then presents the method used and the findings of the research. Finally, a brief discussion concludes presenting the limitations of the study and directions for future research.

\section{Review of Literature and Hypotheses}

\section{Consumer Sociability Behaviour}

Companies post messages accompanied with texts, pictures, videos on a company's Facebook page and encourage consumers to respond, either in an active (e.g., posting) or in a passive (e.g., viewing) way. Passive participation is referred to as viewing the platform without interacting ( $\mathrm{Su}$ et al., 2015). On the contrary, active participation is defined as posting behaviour and includes three forms of consumer sociability behaviour that we are considering in the paper: liking, sharing and commenting on SNSs.

Recent studies have suggested monitoring consumer sociability as a proxy of consumer engagement and thus of the effectiveness of messages (Swani et al., 2013). The first type of behaviour that we consider is liking a message on a company's Facebook page. Liking behaviour allows consumers to express their positive feelings for the messages sharing this information with their network. The second type of sociability behaviour concerns Commenting, and consists in the possibility to express opinions and emotions on a company's Facebook page (Kabadayi \& Price, 2014). The last type of sociability behaviour involves getting the consumers to share the company's message on Facebook. Sharing behaviour allows consumers to share the company's content with the friends in their network on their wall. With respect to liking, commenting, and sharing behaviour, research shows that consumers may be influenced by the characteristics of company messages $(\mathrm{Su}$ et al., 2015). More specifically, previous studies analysed diverse types of message format (e.g., text, photo, video) and type of message (e.g., informational, entertainment, remuneration, social) (Cvijikj \& Michahelles, 2013; Su et al., 2015; Luarn et al., 2015). We extend current literature by evaluating more nuanced characteristics of messages.
The characteristics of messages that are relevant to this research: 1) vividness and interactivity of the message, and, 2) the degree of emotionality of the message. We consider these characteristics as antecedents of sociability behaviour with respect to likes, shares and comments on a company's Facebook page.

\section{Implicit Characteristics of the Message: Vividness and Interactivity}

Vividness describes one characteristic of company messages and is defined in terms of breadth and depth (richness) of the messages that may stimulate the consumers' sensations (Fortin \& Dholakia 2005). The breadth defines the number of diverse sensory cues in the message, such as colours and graphics, while the depth consists in its quality and resolution. Thus, company messages may possess different combinations of cues and diverse levels of vividness (e.g., low or high) stimulating consumer's senses (De Vries et al., 2012). As an example, a picture with motion possesses more vividness than a static picture. Consistent with recent empirical findings, the number of likes could be enhanced by vividness (De Vries et al., 2012), and consumers may demonstrate diverse engagement toward company messages containing various levels of vividness. It follows that:

H1: High vividness generates more increased sociability (likes, comments, shares) than low vividness.

To date, there are various definitions of interactivity. Based on recent literature, interactivity refers to "the degree to which two or more communication parties can act on each other, on the communication medium or on the messages and the degree to which such influences are synchronized" (Tafesse, 2015 based on Liu, Shrum (2002; p.54)). This definition encompasses three aspects: two-way communication, active role and synchronicity. In consistence with previous studies (De Vries et al., 2012; Luarn et al., 2015), company messages may feature several levels of interactivity. For instance, company messages may include questions which stimulate consumers to like or comment on Facebook (i.e., a high level of interactivity).

Empirical findings suggest that the number of comments can increase with interactivity of the message (De Vries et al., 2012). Additionally, a recent study (Luarn et al., 2015) has shown that a high level of interactivity generates more likes, comments and shares on a company's Facebook page. Hence, this study suggests that high degree of interactivity leads to increased consumer sociability behaviour. The next hypothesis is as follows:

H2: High interactivity generates more consumer sociability behaviour outcomes (likes, comments, shares) than low interactivity.

\section{Emotional Content of the Message: Emoji, Emoticons and Textual Emotionality}

Emoticons and emoji are visual non-verbal cues which may be used to enrich the meaning of company messages (textual) on SNSs. Such cues are of many kinds and are used to convey the expression of emotion and the valence of that emotion. Emoticons and emoji are heavily used by 
consumers (Vidal et al., 2016), and may of course be used by companies. Emoticons are displayed in typographical (textual) symbols such as happy, “:)", or sad, ":(". In contrast, emoji are graphical characters of facial expressions (Vidal et al., 2016). Emoticons and emoji may be used to intensify or tune down the emotional tone of a message (Derks et al., 2008), fulfilling an essential aspect of nonverbal online conversations on SNSs.

The use of emotional expressions may be important for consumer sociability behaviour on SNSs. Previous research has shown that messages accompanied with emoticons and emoji are associated with positive (e.g., happiness) or negative sentiments (e.g., anger) (Settanni \& Marengo, 2015). A recent study (Savolainen, 2015) indicates that emotional expressions play an important role in information sharing in the virtual environment, and previous research has shown that messages accompanied with emotions encourage users to respond to the message (Dobele et al., 2007). Hence, a link could be established between emoticons and emoji and consumer sociability behaviour. We thus propose that emoticons and emoji generate more likes, shares, comments. The next hypothesis is as follows:

H3: The presence of emoticons and emoji increases consumer sociability behaviour (likes, comments, shares).

Textual emotionality is believed to be directly related to consumer sociability behaviour. Emotions may be conceptualised in different ways. Frequently used conceptualisation such as positive and negative emotions (Laros \& Steenkamp, 2005) can be applied to textual messages. For example, textual messages can be identified as positive or negative if they include at least one positive or negative word (Kramer et al., 2014).

Prior works emphasise the connection between user emotional states expressed in their status updates, comments on Facebook and emotional well-being (Kramer, 2010; Settanni \& Marengo, 2015). Textual messages containing positive or negative words also may elicit emotional states on Facebook (Kramer et al., 2014) and become viral (Hatfield et al., 1994). Consumer emotional states may thus affect their sociability such as liking, sharing or commenting on Facebook. The next hypothesis is as follows:

H4: The presence of positive words in the message increases consumer sociability behaviour (likes, comments, shares).

\section{Research Design}

The study adopts a mixed approach combining qualitative and quantitative studies. The qualitative approach is used to study the relationship between message characteristics and sociability behaviour in terms of likes, comments, shares (H1- H3). Thus, the content analysis was applied to test for hypothesis $\mathrm{H} 4$.

\section{Methods}

\section{Data Collection}

The criteria applied for selecting the service-based company's Facebook page included the following: (1) existence of an official company's Facebook page, (2) category of the page related to services, (3) English as primary language for communication (Cvijikj \& Michahelles, 2013; Pelletier et al., 2015). For this study, several variables were selected: (1) the implicit characteristics of the message content (i.e., vividness and interactivity), (2) the number of emoticons and emoji; (3) the number of likes, comments and shares. The data were obtained from the messages of the official pages of international hotel companies on Facebook, from 14 January 2015 to 14 January 2016. To ensure accuracy of the data collected we used Revinate Software. This software enabled to track all the posts for the selected period. Following this procedure a total of 144 messages were obtained.

\section{Data Coding}

The study used content analysis, a technique already applied by researchers to investigate company messages on Facebook (Su et al., 2015; Tafesse, 2015; Luarn et al., 2015). The analysis was performed by two independent coders (research assistants) who were trained to interpret several company messages (Swani et al., 2013). The coding scheme was based on previous studies (De Vries et al., 2012; Cvijikj \& Michahelles, 2013; Luarn et al., 2015). In the context of this study, coding applies to the characteristics of message content (vividness, interactivity and emotional). Inter-rater reliability calculated using a formula developed in previous studies (Luarn et al., 2015) was approximately 0.89 , thus falling within the acceptable range of 0.66-0.95 (Su et al., 2015).

\section{Operationalisation of the Independent Variables Vividness and Interactivity}

Based on previous studies (De Vries et al., 2012; Cvijikj \& Michahelles, 2013; Luarn et al., 2015), the study coded four levels of vividness of company's message (no vividness, low, medium, high vividness). No vividness included a short written text and was used as base level in the analysis. The low level of vividness involves photos and images. The medium level of vividness considers links (e.g., links to news web sites, blogs). The high level of vividness included videos (e.g., from YouTube).

Consistent with previous studies (De Vries et al., 2012; Cvijikj \& Michahelles, 2013; Luarn et al., 2015), this study coded four levels of interactivity of the company message (no interactivity, low, medium and high interactivity). No interactivity included static content and was used as the base level in content analysis. The low level of interactivity includes passive links. The medium level of interactivity involves a special request for consumers to interact (e.g., like the message, comment on contest and win prizes). The high level of interactivity includes questions and quizzes.

\section{Textual Content of the Message: Emoji and Emoticons}

Adapted from previous studies (Settanni \& Marengo, 2015), emoji and emoticons were coded as the number of emoji and emoticons, where the base level (i.e., zero) means no emoji or emoticons. 


\section{Operationalisation of the Dependent Variables Consumer Sociability Behaviour}

Consistent with the literature, to operationalise sociability behaviour on a company's Facebook page, we selected likes, comments, shares (De Vries et al., 2012; Swani et al., 2013; Chauhan \& Pillai, 2013; Su et al., 2015; Kwok et al., 2015).

\section{Category of Positive and Negative Emotions}

This category consists of positive and negative emotions with higher scores showing greater intensity of positive or negative emotions (Bazarova et al., 2012). For example, the category of negative emotions has subcategories such as anxiety, anger, sadness, and examples of words are sad, hate, etc.

\section{Results}

Descriptive statistics. This section presents descriptive statistics relative to the measures used in the study. The average number of followers of a company's Facebook page was 2460 in 14 January 2016. Messages with text and photos (low vividness) ( $80 ; 55.6$ per cent) were posted most frequently followed by messages with medium vividness $(52 ; 36.1$ per cent), high vividness $(11 ; 7.6$ per cent), and no vividness ( $1 ; 0.7$ per cent). Respect to message interactivity, messages with no interactivity were the most frequent $(71 ; 49.3$ per cent), followed by low interactivity (43; 29.9 per cent), high interactivity (17; 11.8 per cent), and medium interactivity (13; 9 per cent).

The analysis further indicated that the average number (M) of words per message was 17.93. However, the maximum number of words per message was 75 . The messages with positive words were posted most frequently (92; 63.9 per cent), relative to those with neutral words $(52$; 36.1 per cent). Only 13 messages ( 9 per cent) contained negative words.

Table 1

Descriptive Statistics of Different Consumer Sociability Behaviour Outcomes

\begin{tabular}{|r|c|c|c|c|c|c|}
\hline Sociability behaviour & Average & SD & Minimum & Maximum & Skewness & Kurtosis \\
\hline Like & 12.77 & 16.56 & 0 & 132 & $3.65(0.2)$ \\
\hline Comment & 0.95 & 7.322 & 0 & 33 & $8.743(0.40)$ \\
\hline Share & 0.694 & 3.234 & 0 & 86 & $78.28(0.4)$ \\
\hline
\end{tabular}

The descriptive statistics of different types of consumer sociability behaviour are illustrated in Table 1 . The data shows that the average number of likes was 12.77 $(\mathrm{SD}=16.56)$, the average number of comments was 0.95 $(\mathrm{SD}=7.322)$, and the average number of shares was 0.694 $(\mathrm{SD}=3.234)$. A detailed analysis of different behavioural outcomes of consumer sociability is discussed in the following section.

\section{Hypotheses Test}

\section{Hypothesis $H 1$}

Consistent with the previous work (Luarn et al., 2015), the study employed the analysis of variance (ANOVA) in order to determine whether there were any statistically significant differences between the observed variable means. The distributions of the dependent variables (likes, comments and shares) were heavily skewed thus a logarithmic transformation was applied. The results showed that $\mathrm{H} 1$, according to which, higher vividness generates a higher amount of consumer sociability behaviour (likes, comments and shares), was statistically significant relatively to likes, but not relatively to comments and shares (Like: $\quad \mathrm{F}(3 ; 140)=16.8>3.984 ; \quad \mathrm{p}<0.01$; $\quad$ Comment: $F(3 ; 140)=0.26<3.984 ; p<0.01$; Share: $F(3 ; 140)=1.83<3.984$; $\mathrm{p}<0.01)$ (Table 2). Contrary to expectations, consumers were thus more likely to like with a low level of vividness (Like: $\mathrm{M}=2.56, \mathrm{SD}=0.86$ ). Per the findings above; therefore, $\mathrm{H} 1$ was not supported.

Table 2

ANOVA Analysis for the Effect of Information Vividness (Company Message)

\begin{tabular}{|c|c|c|c|c|c|c|}
\hline Dependent variable & Vividness & $\mathbf{N}$ & $\mathbf{M}$ & SD & $\mathbf{F}$ & $\mathbf{P}$ \\
\hline \multirow[t]{4}{*}{ Like } & No & 1 & 3.09 & - & \multirow{4}{*}{16.8} & \multirow{4}{*}{$0.001 *$} \\
\hline & Low & 80 & 2.56 & 0.86 & & \\
\hline & Medium & 52 & 1.67 & 0.81 & & \\
\hline & High & 11 & 1.17 & 1.01 & & \\
\hline \multirow[t]{4}{*}{ Comment } & No & 1 & 0.0 & - & \multirow{4}{*}{0.26} & \multirow{4}{*}{0.85} \\
\hline & Low & 80 & 0.18 & 0.34 & & \\
\hline & Medium & 52 & 0.24 & 0.76 & & \\
\hline & High & 11 & 0.12 & 0.28 & & \\
\hline \multirow[t]{4}{*}{ Share } & No & 1 & 1.09 & - & \multirow{4}{*}{1.83} & \multirow{4}{*}{0.15} \\
\hline & Low & 80 & 0.29 & 0.44 & & \\
\hline & Medium & 52 & 0.17 & 0.65 & & \\
\hline & High & 11 & 0.09 & 0.33 & & \\
\hline
\end{tabular}

Notes: n, number of messages; M, mean; SD, standard deviation; F, f-value, $p, p$-value.*p<0.01

\section{Hypothesis $\mathrm{H} 2$}

Based on the results of a one-way ANOVA (Table 3), consumers were more likely to like information presented with no (Like: $\mathrm{M}=2.55, \mathrm{SD}=0.88$ ) or medium level of interactivity (Like: $\mathrm{M}=2.21, \mathrm{SD}=0.85$ ). Therefore $\mathrm{H} 2$ was not even supported. 
ANOVA Analysis for the Effect of Information Interactivity (Company Message)

\begin{tabular}{|c|c|c|c|c|c|c|}
\hline Dependent variable & Interactivity & $\mathbf{N}$ & $\mathbf{M}$ & SD & $\mathbf{F}$ & $\mathbf{P}$ \\
\hline Like & No & 71 & 2,55 & 0.88 & \multirow{4}{*}{11.918} & \multirow{4}{*}{$0.001^{*}$} \\
\hline & Low & 43 & 1.63 & 0.89 & & \\
\hline & Medium & 13 & 2.21 & 0.85 & & \\
\hline & High & 17 & 1.62 & 0.92 & & \\
\hline \multirow[t]{4}{*}{ Comment } & No & 71 & 0.17 & 0.32 & \multirow{4}{*}{1.70} & \multirow{4}{*}{0.170} \\
\hline & Low & 43 & 0.24 & 0.72 & & \\
\hline & Medium & 13 & 0.45 & 0.87 & & \\
\hline & High & 17 & 0.04 & 0.17 & & \\
\hline \multirow[t]{4}{*}{ Share } & No & 71 & 0.29 & 0.44 & \multirow{4}{*}{2.12} & \multirow{4}{*}{0.101} \\
\hline & Low & 43 & 0.14 & 0.57 & & \\
\hline & Medium & 13 & 0.46 & 0.89 & & \\
\hline & High & 17 & 0.08 & 0.23 & & \\
\hline
\end{tabular}

Notes: n, number of messages; M, mean; SD, standard deviation; F, f-value, p, p-value.*p<0.01

\section{Hypothesis H3}

Emoticons and emoji were counted to test $\mathrm{H} 3$. According to $\mathrm{H} 3$, information which presented with emoticons and emoji should lead to increased sociability behaviour (likes, comments, shares) than information with no emoji or emoticons. Based on the results of the correlation analysis (Kendall), the results indicated that there was a significant positive correlation between emoticons and emoji and liking $(r=0.220 ; \mathrm{p}<0.01)$ (Table 4). Thus hypothesis H3 was partially supported.

Correlation Among Variables ( $N=144)$

Table 4

\begin{tabular}{|r|c|c|c|c|}
\hline Variables & Emoticons and emoji & Like & Comment & Share \\
\hline Emoticons and emoji & - & $0.220^{* *}$ & -0.015 & 0.108 \\
\hline Like & $0.220^{* *}$ & - & $0.320^{* *}$ & $0.449^{* *}$ \\
\hline Comment & -0.015 & $0.320^{* *}$ & - & 0.138 \\
\hline Share & 0.108 & $0.449^{* *}$ & 0.138 & - \\
\hline
\end{tabular}

Notes: $* \mathrm{p}<=0.05 ; * * \mathrm{p}<0.01$

\section{Hypothesis $\mathrm{H} 4$}

The findings show that there were significant positive correlations between positive words and consumer sociability behaviour (Like: $\mathrm{r}=0.185, \mathrm{p}<0.05$; Comment: $\mathrm{r}=0.229, \mathrm{p}<0.01$; Share: $r=0.194, \mathrm{p}<0.05)$ as shown in Table 5 . These correlations were modest, ranging from
0.185 to 0.229 . The highest correlation was identified between company message text with positive text and commenting action (Comment: $r=0.229, \mathrm{p}<0.01$ ). Negative words produced non-significant correlations. Therefore $H 4$ was supported.

Correlation Among Variables ( $\mathrm{N}=144)$

Table 5

\begin{tabular}{|r|l|l|l|l|l|}
\hline Variables & Positive words & Negative words & Like & Comment & Share \\
\hline Positive words & - & 0.096 & $0.185^{*}$ & $0.229^{* *}$ \\
\hline Negative & 0.096 & - & -0.023 & $0.194^{*}$ \\
\hline Like & $0.185^{*}$ & -0.023 & - & 0.009 & $0.614^{* *}$ \\
\hline Comment & $0.229^{* *}$ & 0.009 & $0.614^{* *}$ & - & $0.611^{* *}$ \\
\hline Share & $0.194^{*}$ & 0.046 & $0.611^{* *}$ & $0.925^{* *}$ & $-5^{* *}$ \\
\hline
\end{tabular}

Notes: $* \mathrm{p}<=0.05 ; * * \mathrm{p}<0.01$

\section{Discussion}

The findings showed that the information presented with high vividness does not increase consumer sociability behaviour. These findings are against the mainstream literature, however they are consistent with a recent study by Tafesse (2015). A possible concurring explanation could be that videos require more time to view in comparison to pictures and may just be skipped. Pictures, by contrast, may act as a quick trigger and generate automatic responses. As a result, marketers who wish to engage their audience are recommended to post messages with photos rather than videos.

Regarding levels of interactivity, a medium level of interactivity reveals a higher level of consumer comments and shares. In contrast, information with no interactivity showed higher level of consumer likes, thus contrasting what has been hypothesized. A possible explanation, again, might be related to viewing time, because messages with no interactivity use less time. These results give voice to the studies indicating that information with a high level of interactivity may lead to decreased, rather than increased engagement (Cvijikj \& Michahelles, 2013; Sabate et al., 2014; Tafese, 2015). The suggestion for companies could be to use a medium level of interactivity in order to stimulate sociability.

With regard to the emotional content of the message, a message containing emoticons and emoji increases 
sociability behaviour in terms of likes. Here the findings are consistent with the hypotheses. The latter show that the presence of emoticons and emoji increases liking, and that positive words in the message increase consumer sociability behaviour. The results thus confirm that consumers prefer to view positive emotion induced messages on a company's Facebook page. Marketers are highly recommended to post more emotional text accompanied by emoji and emoticons.

\section{Limitations and Future Research}

This study derives insights into consumer sociability behaviour on a company's Facebook page providing several inspiring directions for future research. On a side note, although the scope of the paper was not to focus on a specific industry, the study admittedly provides the analysis of international hotel messages on Facebook and does not represent the whole service industry. The findings can not therefore be generalised for the whole industry.

A second limitation is that the study does not include cognitive and emotional consumer responses as mediating factors for consumer sociability. For example, a recent study has revealed that using SNSs may induce a positive affective state for users (Mauri et al., 2011). Thus, consumer comments may relate to emotions and feelings (Sabate et al., 2014). Given that the current study reveals that there is a relationship between positive words and consumer sociability behaviour on Facebook further research in this direction is recommended.

Further, this research is limited in so far as it does not consider process measures which could be of interest, such as for example the time of the day (e.g., during business hours, non-business hours). For example, Sabate et al., (2014) indicated that the timing of company messages plays a key role in consumer sociability. Moreover, company messages posted during working hours were more likely to be commented on (Sabate et al., 2014) and messages posted on working days featured higher number of comments (Cvijikj \& Michahelles, 2013). Future research may include these aspects.
A final limitation is related to new updates of Facebook. Recently, Facebook has launched emoji "Reactions" button including Love, Haha, Wow, Sad, Angry reactions (Chaykowski, 2016). These reactions provide a new way for users to quickly respond to messages. Furthermore, these reactions worked consistently well across cultures (Chaykowski, 2016). Thus, future research may explore how different messages are related to diverse emoji reactions and how they enhance current findings.

\section{Conclusions}

This study provides insights to the literature on consumer sociability behaviour on Facebook. The findings indicate that various characteristics of company messages generate different sociability behaviour on a company's Facebook page. As for the vividness of a message, the findings show that a low or medium level of vividness encourages higher number of likes, shares, comments. In this regard, pictures remain more interesting (low vividness) for consumers than videos (high vividness).

We also show that company messages containing a medium level of interactivity show a higher number of comments and shares than the highest possible level of interactivity. These results seem to imply that the highest level of interactivity require more efforts than a simple autonomous "Like" response. Therefore marketers should use messages with no or medium interactivity in order to encourage consumer sociability behaviour on Facebook. Concerning emoji and emoticons, the findings show that they increase the number of likes. Consistent with Facebook updates, marketers should use more emoji and emoticons in company messages to foster consumer sociability behaviour. Finally, company messages with positive words are more powerful than negative words in encouraging consumer sociability behaviour.

Marketers should thus focus on text-emotionality when posting messages on Facebook. These findings began to shed light on the characteristics of company messages related to research analysing consumer sociability behaviour on SNSs. Future research may enrich our findings and enable generalisation.

\section{References}

Bazarova, N. N., Taft, J. G., Choi, Y. H., \& Cosley, D. (2012). Managing impressions and relationships on Facebook: Selfpresentational and relational concerns revealed through the analysis of language style. Journal of Language and Social Psychology, 32 (2), 121-141. https://doi.org/10.1177/0261927X12456384

Carr, C.T., Schrock, D.B., \& Dauterman, P. (2012). Speech acts within Facebook status messages. Journal of Language and Social Psychology, 31(2), 1-21. https://doi.org/10.1177/0261927X12438535

Chauhan, K., \& Pillai, A. (2013). Role of content strategy in social media brand communities: a case of higher education institutes in India. Journal of Product \& Brand Management, 22(1), 40-51. https://doi.org/10.1108/106104 21311298687

Chaykowski, K. (2016) Facebook no longer just has a 'like' button, thanks to global launch of emoji 'Reactions'.[online] Forbes. Available at: www.forbes.com/sites/kathleenchaykowski/2016/02/24/facebook-no-longer-just-has-a-likebutton-thanks-to-global-launch-of-emoji-reactions/\#6ee48ff94994 [Accessed 9 Mar. 2016]

Cvijikj, I. P., \& Michahelles, F. (2013). Online engagement factors on Facebook brand pages. Social Network Analysis and Mining, 3(4), 843-861. https://doi.org/10.1007/s13278-013-0098-8

De Vries, L., Gensler, S., \& Leeflang, P. S. (2012). Popularity of brand posts on brand fan pages: An investigation of the effects of social media marketing. Journal of Interactive Marketing, 26(2), 83-91. https://doi.org/10.1016/j. intmar.2012.01.003 
Derks, D., Fischer, A. H., \& Bos, A. E. (2008). The role of emotion in computer-mediated communication: A review. Computers in Human Behavior, 24(3), 766-785. https://doi.org/10.1016/j.chb.2007.04.004

Dobele, A., Lindgreen, A., Beverland, M., Vanhamme, J., \& van Wijk, R. (2007). Why pass on viral messages? Because they connect emotionally. Business Horizons, 50(4), 291-304. https://doi.org/10.1016/j.bushor.2007.01.004

Fortin, D. R., \& Dholakia, R. R. (2005). Interactivity and vividness effects on social presence and involvement with a webbased advertisement. Journal of Business Research, 58(3), 387-396. https://doi.org/10.1016/S0148-2963(03)001061

Gamboa, A. M., \& Gonçalves, H. M. (2014). Customer loyalty through social networks: Lessons from Zara on Facebook. Business Horizons, 57(6), 709-717. https://doi.org/10.1016/j.bushor.2014.07.003

Gensler, S., Volckner, F., Liu-Thompkins, Y., \& Wiertz, C. (2013). Managing brands in the social media environment. Journal of Interactive Marketing, 27(4), 242-256. https://doi.org/10.1016/j.intmar.2013.09.004

Hatfield, E., Cacioppo, J.T. \& Rapson, R.L. (1994). Emotional contagion, United Kingdom, UK: Cambridge University Press. Kindle edition.

Hennig-Thurau, T., Malthouse, E. C., Friege, C., Gensler, S., Lobschat, L., Rangaswamy, A., \& Skiera, B. (2010). The impact of new media on customer relationships. Journal of Service Research, 13 (3), 311-330. https://doi.org/10. 1177/1094670510375460

Kabadayi, S., \& Price, K. (2014). Consumer-brand engagement on Facebook: liking and commenting behaviors. Journal of Research in Interactive Marketing, 8(3), 203-223. https://doi.org/10.1108/JRIM-12-2013-0081

Kramer, A. D. (2010, April). An unobtrusive behavioral model of gross national happiness. In Proceedings of the SIGCHI conference on human factors in computing systems (pp. 287-290). ACM. https://doi.org/10.1145/1753326.1753369

Kramer, A. D., Guillory, J. E. \& Hancock, J. T., (2014). Experimental evidence of massive-scale emotional contagion through social networks. In Proceedings of the National Academy of Sciences of the United States of America, 111 (24), 8788-8790. https://doi.org/10.1073/pnas.1320040111

Kumar, A., Bezawada, R., Rishika, R., Janakiraman, R., \& Kannan, P. K. (2016). From Social to Sale: The Effects of FirmGenerated Content in Social Media on Customer Behavior. Journal of Marketing, 80 (1), 7-25. https://doi.org/10. 1509/jm.14.0249

Kwok, L., \& Yu, B. (2013). Spreading social media messages on Facebook an analysis of restaurant business-to-consumer communications. Cornell Hospitality Quarterly, 54(1), 84-94. https://doi.org/10.1177/1938965512458360

Kwok, L., Zhang, F., Huang, Y. K., Yu, B., Maharabhushanam, P., \& Rangan, K. (2015). Documenting business-toconsumer (B2C) communications on Facebook: What have changed among restaurants and consumers?. Worldwide Hospitality and Tourism Themes, 7 (3), 283-294. https://doi.org/10.1108/WHATT-03-2015-0018

Laros, F. J., \& Steenkamp, J. B. E. (2005). Emotions in consumer behavior: a hierarchical approach. Journal of business Research, 58(10), 1437-1445. https://doi.org/10.1016/j.jbusres.2003.09.013

Luarn, P., Lin, Y. F., \& Chiu, Y. P. (2015). Influence of Facebook brand-page posts on online engagement. Online Information Review, 39(4), 505-519. https://doi.org/10.1108/OIR-01-2015-0029

Liu, Y., \& Shrum, L. J. (2002). What is interactivity and is it always such a good thing? Implications of definition, person, and situation for the influence of interactivity on advertising effectiveness. Journal of advertising, 31(4), 53-64. https://doi.org/10.1080/00913367.2002.10673685

Mauri, M., Cipresso, P., Balgera, A., Villamira, M., \& Riva, G. (2011). Why is Facebook so successful? Psychophysiological measures describe a core flow state while using Facebook. Cyberpsychology, Behavior, and Social Networking, 14(12), 723-731. https://doi.org/10.1089/cyber.2010.0377

Pelletier, M. J., \& Blakeney Horky, A. (2015). Exploring the Facebook Like: a product and service perspective. Journal of Research in Interactive Marketing, 9 (4), 337-354. https://doi.org/10.1108/JRIM-09-2014-0059

Sabate, F., Berbegal-Mirabent, J., Ca-abate, A., \& Lebherz, P. R. (2014). Factors influencing popularity of branded content in Facebook fan pages. European Management Journal, 32(6), 1001-1011. https://doi.org/10.1016/j.emj. 2014.05.001

Savolainen, R. (2015). The role of emotions in online information seeking and sharing: A case study of consumer awareness. Journal of Documentation, 71(6), 1203-1227. https://doi.org/10.1108/JD-09-2014-0129

Settanni, M., \& Marengo, D. (2015). Sharing feelings online: studying emotional well-being via automated text analysis of Facebook posts. Frontiers in psychology, 6, 1-7. https://doi.org/10.3389/fpsyg.2015.01045

Smith, C. (2016). By the Numbers: 200+ Amazing Facebook Statistics (January 2016). Digital Marketing Ramblings (DMR). Available at: www.expandedramblings.com/index.php/by-the-numbers-17-amazing-facebook-stats/ [Accessed 9 Jan. 2016]

Su, N., Reynolds, D., \& Sun, B. (2015). How to make your Facebook posts attractive: A case study of a leading budget hotel brand fan page. International Journal of Contemporary Hospitality Management, 27(8), $1772-1790$. https://doi.org/10.1108/IJCHM-06-2014-0302 
Egle Vaiciukynaite, Francesco Massara, Rimantas Gatautis. An Investigation on Consumer Sociability Behaviour on Facebook

Swani, K., Milne, G., \& Brown, B. P. (2013). Spreading the word through likes on Facebook: Evaluating the message strategy effectiveness of Fortune 500 companies. Journal of Research in Interactive Marketing, 7(4), $269-294$. https://doi.org/10.1108/JRIM-05-2013-0026

Tafesse, W. (2015). Content strategies and audience response on Facebook brand pages. Marketing Intelligence \& Planning, 33(6), 927-943. https://doi.org/10.1108/MIP-07-2014-0135

Tausczik, Y. R., \& Pennebaker, J. W. (2010). The psychological meaning of words: LIWC and computerized text analysis methods. Journal of language and social psychology, 29(1), 24-54. https://doi.org/10.1177/0261927X09351676

Vidal, L., Ares, G., \& Jaeger, S. R. (2016). Use of emoticon and emoji in tweets for food-related emotional expression. Food Quality and Preference, 49,119-128. https://doi.org/10.1016/j.foodqual.2015.12.002

Wagstaff, K. (2015). Facebook Dominates Nielsen List of 2015's Most Popular Apps. [online] NBC News. Available at: www.nbcnews.com/tech/social-media/facebook-dominates-neilsen-list-2015s-most-popular-apps-n482706 [Accessed 9 Jan. 2016]

The article has been reviewed.

Received in May, 2016; accepted in October, 2017. 